\title{
Hybrid Beads Bearing Immobilized Bacteria as Advanced Means for the Removal of Acid Blue 93 Dye
}

\author{
TEODOR SANDU ${ }^{1}$, MARIA LUIZA JECU ${ }^{2}$, IULIANA RAUT ${ }^{2}$, MARIANA CALIN ${ }^{2}$, \\ ELVIRA ALEXANDRESCU ${ }^{3}$, TANTA VERONA IORDACHE ${ }^{1}$, \\ MARINELA VICTORIA DUMITRU ${ }^{1}$, ANDREI SARBU ${ }^{*}$
}

${ }^{1}$ National Research- Development Institute for Chemistry and Petrochemistry, Advanced Polymer Materials and Polymer Recycling Group, 202 Splaiul Independenței, 060021, Bucharest, Romania

${ }^{2}$ National Research- Development Institute for Chemistry and Petrochemistry, Biotechnology and Bioanalyses, 202 Splaiul Independenței, 060021, Bucharest, Romania

${ }^{3}$ National Research- Development Institute for Chemistry and Petrochemistry, Heterogeneous Systems, 202 Splaiul Independentei, 060021, Bucharest, Romania

\begin{abstract}
This paper describes the preparation of three-component hybrid copolymer beads, with water purification features. These newly developed hybrid beads were prepared starting from a mixture of poly(acrylonitrile- co- methacrylic acid) (PAN-co-PMAA), polyvinyl alcohol (PVA) and magnetite $\left(\mathrm{Fe}_{3} \mathrm{O}_{4}\right)$, respectively. The preparation itself involved a Wet Phase Inversion (WPI) process. A Pseudomonas sp. strain was immobilized onto previously mentioned beads, before and after activation of the beads surface with glutardialdehyde, and afterwards used for the amendment of simulated water bearing an azo-blue dye, i.e. Acid Blue 93. In order to highlight the immobilization of Pseudomonas sp. strain, FTIR spectra and TGA results were recorded. CFU measurements as well as SEM images further provided evidence towards the occurrence of immobilization. The biodegradation studies of Acid Blue 93 were carried out by means of UV spectroscopy at various contact times (24; 72 and $144 h$ ) of the hybrid beads with the targeted dye.
\end{abstract}

Keywords: hybrid beads, magnetite, Pseudomonas sp., Acid Blue 93, water amendment

\section{Introduction}

The wide use of dyes for fibers and paints results in a large amount of wastewaters. If not entirely purified, these wastewaters pose great threat to the environment and human health especially when they reach surface and afterwards groundwaters [1]. In many countries, like Norway and Romania, the major source of drinking water is from surface water reservoirs. Therefore, a great deal of research was conducted, seeking advanced means of reducing the impact of such dyes. One negative effect of dyes may be attributed to their slow biodegradability. Among the already known methods that were proven to be somewhat efficient for dyes removal, it is worth mentioning: adsorption, coagulation, photocatalytic oxidation, and biodegradation. However, all these approaches are highly energy-consuming and, thus, their cost-efficiency is rather low.

Different from physical and chemical methods, biological ones lead simultaneously to lower costs, due to low energy consumption, and to higher efficiency related to the treatment of higher volumes of water. In this context, it becomes worth mentioning the use of bacterial strains for azo-dyes removal, as they prove to be able to cleave the azo bond. The use of bacterial strains emerged as a need to overcome the former mentioned hurdles of conventional methods. In addition, immobilization of such strains on various substrates allows for repeated uses of materials. The only minor inconvenient of working with bacterial strains refers to using nutrients, to ensure their proper growth [2-16].

In this work, innovative hybrid beads based on poly(acrylonitrile-co-methacrylic acid) (PAN-coPMAA) and polyvinyl alcohol (PVA) were developed as substrates for bacteria immobilization and used for dyes removal from aqueous solutions. Polyacrylonitrile and its copolymers are well-known

*email: andr.sarbu@gmail.com 
precursors for membranes and beads as they possess excellent film/beads- forming properties, together with enhanced thermal, mechanical and chemical stability. Polyvinyl alcohol is another widely used polymer, having outstanding properties like hydrophilicity, biocompatibility and water solubility [1720]. Therefore, each component contributes with specific features to the final hybrid beads, for instance the PAN-co-PMAA main matrix allows for the formation of bead shaped particles and PVA provides biocompatibility and, thus, for a proper environment for the following Pseudomonas immobilization.

Magnetic nanoparticles found use in a wide range of applications, i.e. chromatography, separation of cells and proteins, removal of dyes and heavy metals, but most importantly in the immobilization of microorganisms [21-23]. In this study, the incorporation of magnetite particles $\left(\mathrm{Fe}_{3} \mathrm{O}_{4}\right)$ into the precursor solutions of beads eases the following separation process of materials after dyes removal via magnetic separation methods.

\section{Materials and methods}

\subsection{Materials}

Acrylonitrile (AN) and methacrylic acid (MAA), used for the preparation of PAN-co-PMAA, were supplied by Merck and distilled before use, for the inhibitor removal. Copolymerization was promoted using a redox initiation system (potassium peroxidisulfate- KPS and sodium metabisulfite- MS) and conducted under acidic $p \mathrm{H}$ ( $p \mathrm{H}$ adjusted using $\mathrm{H}_{2} \mathrm{SO}_{4}$, Merck).

The preparation of polyvinyl alcohol (PVA) was carried out in two steps: preparation of polyvinyl acetate (PVAc) followed by methanolysis of PVAc. Preparation of PVAc involved the use of the following raw materials: vinyl acetate (VAc; monomer, p.a. Merck) and AIBN (azobisisobutyronitrile, p.a. Merck; initiator) to obtain polyvinyl acetate (PVAc). Methanolysis of PVAc, to yield PVA, consisted of a polymer analogous reaction between PVAc and methanol (Merck; trans-esterification agent), under basic catalysis ( $\mathrm{NaOH}$ pellets, Sigma Aldrich).

In order to obtain the precursor solution of beads, magnetite $\left(\mathrm{Fe}_{3} \mathrm{O}_{4}\right.$, Sigma Aldrich) and dimethylsulfoxide (DMSO, solvent, Merck) were used as received. Beads preparation involved dripping the precursor solution with a syringe into a coagulation bath, consisting of distilled water and isopropyl alcohol (Merck).

A Pseudomonas putida strain from INCDCP-ICECHIM Microbial Collection was used as bacterial constituent. Pseudomonas putida was cultured on Luria Bertani medium (LB) with following composition (g/L): 10, tryptone; 5 , yeast extract; $10, \mathrm{NaCl}, 1000 \mathrm{~mL}$ distilled water. The culture medium was sterilized at $121^{\circ} \mathrm{C}$ for $15 \mathrm{~min}$.

Immobilization of Pseudomonas putida was performed using two routes: direct immobilization on beads and immobilization on chemically activated beads, respectively. Chemical activation of beads was conducted using glutardialdehyde (GA, aqueous solution, $50 \%$ ), as activation agent and $\mathrm{H}_{2} \mathrm{SO}_{4}$, as catalyst.

Acid Blue 93 dye was used in the bioremediation tests. This dye was supplied by Merck, under the trade name Blue Ink 242 (technical purity). The main characteristics of the used dye are summarized in Table 1. 
Table 1. Technical specification for Acid Blue 93

\begin{tabular}{l|l}
\hline Chemical formula: & \\
\hline Chemical structure: & \\
& 79 \\
\hline Molecular weight, $\mathrm{g} / \mathrm{mol}$ & 250 \\
\hline Melting point, ${ }^{\circ} \mathrm{C}$ & 70 \\
\hline Solubility in water, $\mathrm{g} / \mathrm{L}$ &
\end{tabular}

\subsection{Sample preparation}

\subsubsection{Preparation of hybrid beads}

The hybrid beads were prepared in three steps, as follows: (i) preparation of copolymers, i.e. PANco-PMAA and PVA; (ii) preparation of precursor solution with magnetite content $\left(\mathrm{Fe}_{3} \mathrm{O}_{4}\right)$, and (iii) coagulation of solution in bead form.

Copolymerization of AN with MAA was performed in emulsion at $47^{\circ} \mathrm{C}$ using a redox initiation system (MS-KPS) in aqueous medium at acidic $p \mathrm{H}\left(\mathrm{H}_{2} \mathrm{SO}_{4}\right)$. The last component added to the reaction medium was KPS and 90 min have been timed since its addition. The obtained copolymer was separated from the reaction medium, washed repeatedly with distilled water in order to remove unreacted monomers and finally dried at $60^{\circ} \mathrm{C}$, in an oven, and grounded. The recipe for the preparation of PANco-PMAA is given in Table 2.

Table 2. Recipe for PAN-co-PMAA preparation

\begin{tabular}{cccccc}
\hline $\mathrm{H}_{2} \mathrm{O}, \mathrm{mL}$ & $\mathrm{AN}, \mathrm{mL}$ & $\mathrm{MAA}, \mathrm{mL}$ & $\mathrm{H}_{2} \mathrm{SO}_{4} 98 \%, \mathrm{~mL}$ & $\mathrm{MS}, \mathrm{g}$ & $\mathrm{KPS}, \mathrm{g}$ \\
\hline 425.0 & 75.0 & 14.8 & 0.12 & 0.375 & 0.375 \\
\hline
\end{tabular}

For preparing PVA, PVAc was first synthesized by radical polymerization of VAc in $\mathrm{MeOH}(10: 90$ molar ratio) at $65^{\circ} \mathrm{C}, 2 \mathrm{~h}$, under refluxing, using AIBN $(0.5 \mathrm{wt}$. \% relative to VAc) as initiator. Further on, methanolysis of PVAc took place under basic catalysis $\left(1.5 \mathrm{wt} . \% \mathrm{NaOH}\right.$ relative to PVAc) at $45{ }^{\circ} \mathrm{C}$, 1 hour, to yield a $98 \%$ acetalization degree.

The second step consisted of preparing the precursor solutions of beads, containing magnetite particles. In order to optimize the process of beads preparation and evaluate the effect of the addition order of components, two experimental variants were investigated (Table 3).

Table 3. Experimental variants

\begin{tabular}{ll}
\hline Magnetic beads & Order of components \\
\hline 1 & PVA, $\mathrm{PAN}-$ co-PMAA, $\mathrm{Fe}_{3} \mathrm{O}_{4}$ \\
\hline 2 & $\mathrm{PVA}, \mathrm{Fe}_{3} \mathrm{O}_{4}$, PAN-co-PMAA \\
\hline
\end{tabular}

For the first trial, the following addition sequence was considered: in $21 \mathrm{~mL}$ of DMSO heated at 80 ${ }^{\circ} \mathrm{C}, 0.4 \mathrm{~g}$ PVA was dissolved followed by dissolution of $1.6 \mathrm{~g}$ PAN-co-PMAA and dispersion of $0.04 \mathrm{~g}$ $\mathrm{Fe}_{3} \mathrm{O}_{4}$. In the second trial the same amounts of components were used with the difference that $\mathrm{Fe}_{3} \mathrm{O}_{4}$ was added immediately after PVA dissolution in DMSO and PAN-co-PMAA was dissolved last. In the third stage, hybrid beads were obtained. In this respect, the precursor solution was dripped with a syringe into a coagulation bath consisting of a water-isopropyl alcohol mixture $(300 \mathrm{~mL}, 50: 50$ vol. \%). The beads were left into this coagulation bath for $24 \mathrm{~h}$ at room temperature and afterwards separated magnetically and washed with distilled water $(100 \mathrm{~mL})$ twice. The hybrid beads were stored in water. 


\subsubsection{Surface activation of hybrid beads}

A part of the hybrid beads from both variants (1 and 2) was chemically activated with GA. This procedure involved the functionalization of beads bearing hydroxyl groups (denoted B-OH) with aldehyde groups (B-CHO) according to Scheme $1 \mathrm{a}$. Aldehyde functionalities on the surface of beads were further available for bacterial immobilization (Scheme $1 \mathrm{~b}$ ). Therefore, two series of functionalized beads, noted 1-GA and 2-GA, were prepared, according to the recipe given in Table 4.

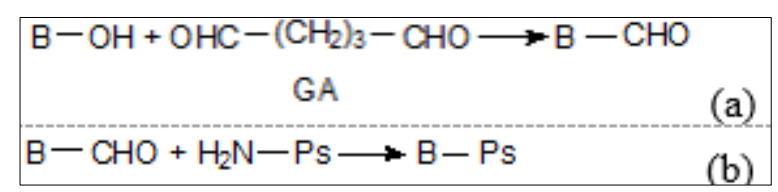

Scheme 1. The mechanism of functionalization and immobilization reactions

Table 4. Chemical activation of beads with GA

\begin{tabular}{cccccc}
\hline $\begin{array}{c}\text { Amount of } \\
\text { beads, } \\
\mathbf{g}\end{array}$ & $\begin{array}{c}\mathbf{G A}, \\
\mathbf{m L}\end{array}$ & $\begin{array}{c}\mathbf{H}_{\mathbf{2}} \mathbf{O}, \\
\mathbf{m L}\end{array}$ & $\begin{array}{c}\mathbf{H}_{2} \mathbf{S O}_{4}, \\
\boldsymbol{\mu L}\end{array}$ & $\begin{array}{c}\text { Temperature, } \\
{ }^{\circ} \mathbf{C}\end{array}$ & $\begin{array}{c}\text { Time, } \\
\text { min. }\end{array}$ \\
\hline 0.2 & 4 & 16 & 300 & 70 & 30 \\
\hline
\end{tabular}

\subsubsection{Cultivation conditions for Pseudomonas putida}

The bacterial strain was replicated on Petri plates with LB medium and incubated at $28^{\circ} \mathrm{C}$ for $24 \mathrm{~h}$. Cultivation was performed in $500 \mathrm{~mL}$ Erlenmayer vessels with $250 \mathrm{~mL} \mathrm{LB}$ medium, on Heidolph Unimax 101 orbital shaker $\left(125 \mathrm{rpm}, 28^{\circ} \mathrm{C}, 4\right.$ days $)$. After incubation, the culture broth was centrifuged for $20 \mathrm{~min}$ at $4000 \mathrm{rpm}$. The deposit (bacterial biomass) of Pseudomonas putida was resuspended in 50 $\mathrm{mM}$ sodium phosphate buffer, $p \mathrm{H} 7.0$ and stored in the refrigerator at $4{ }^{\circ} \mathrm{C}$, in a closed container (Figure $1)$.

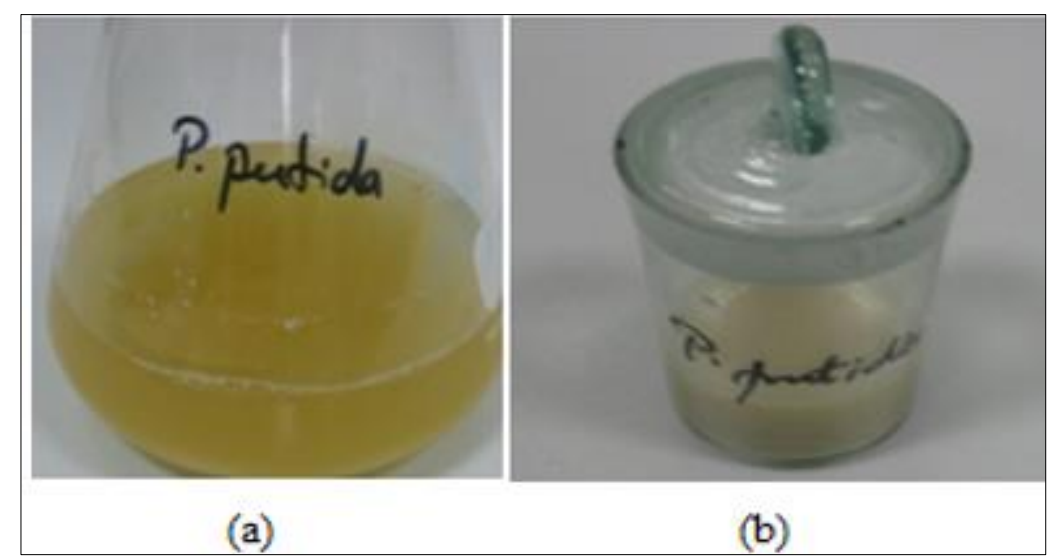

Figure 1. Aspects of obtaining bacterial biomass: (a) Culture of Pseudomonas putida at $48 \mathrm{~h}$ of incubation; (b) Biomass of Pseudomonas putida obtained after centrifugation of culture broth

\subsubsection{Immobilization of Pseudomonas putida cells}

Both variants of hybrid beads ( 1 and 2 ) were contacted before and after activation with GA (nonactivated beads were noted 1 and 2, and activated beads 1-GA and 2-GA, respectively) with $2 \mathrm{mg}$ bacterial biomass from Pseudomonas putida in sterilized plastic ampoules and incubated at room temperature under continuous stirring, for $24 \mathrm{~h}$. The four variants of hybrid beads with immobilized Pseudomonas are centralized in Table 5. 
Table 5. Experimental variants for Pseudomonas (Ps) immobilization

\begin{tabular}{ll}
\hline Sample & Bacterial cells immobilized on different types of beads \\
\hline 1-GA-Ps & Ps biomass immobilized on 1-GA functionalized beads \\
\hline 1-Ps & Ps biomass immobilized on type 1 beads \\
\hline 2-GA-Ps & Ps biomass immobilized on 2-GA functionalized beads \\
\hline 2-Ps & Ps biomass immobilized on type 2 beads \\
\hline
\end{tabular}

\subsubsection{Biodegradation of Acid Blue 93 dye}

For biodegradation tests, the hybrid beads were separated and contacted with $18 \mathrm{~mL}$ of dye stock solution (1\% in water) and introduced into small (sterilized) Erlenmeyer flasks.

\subsection{Characterization Techniques}

The chemical composition of hybrid beads as well as the one of raw materials was analyzed by Fourier Transform Infrared (FTIR). FTIR spectra were registered in ATR mode on a Tensor Vertex (Ettlingen, Germany) device using $32 \mathrm{scans}$ and $4 \mathrm{~cm}^{-1}$ resolution in $4000-400 \mathrm{~cm}^{-1}$ range. Samples were very well vacuum dried at $30^{\circ} \mathrm{C}$ for $48 \mathrm{~h}$, in order to avoid the occurrence of bands assigned to $-\mathrm{OH}$ groups, from water, in the spectra.

Thermal behavior of samples was investigated by recording TGA (Thermal Gravimetric Analysis)/DTG (Differential Thermal Gravimetry) curves. To this end, a TGA Q 5000 device was involved.

Each sample was heated from room temperature to $700{ }^{\circ} \mathrm{C}$, at a heating rate of $10{ }^{\circ} \mathrm{C} / \mathrm{min}$.

The bioremediation process was monitored by ultraviolet- visible (UV-Vis) spectrometry in the 200 $\div 800 \mathrm{~nm}$ spectral range using a device from Thermo Scientific. Solutions were collected at certain time intervals: 24,72 and $144 \mathrm{~h}$, respectively.

Scanning Electron Microscopy (SEM) was performed on FEI-QUANTA 200. The samples were placed on metallic support, aluminum standard stub, using a double-sided adhesive carbon tape. The SEM images were taken at an accelerating voltage of $30 \mathrm{kV}$. Micrographs of the samples were analyzed at different magnifications to identify changes on the surface.

\section{Results and discussions}

\subsection{Fourier Transform Infrared (FTIR) spectrometry}

In order to confirm the immobilization of bacteria on the hybrid beads, FTIR spectra were recorded, before and after immobilization of bacterial cells. The results are grouped into 4 series, as 4 of the samples (1-GA; 1; 2-GA and 2) were used as support for the immobilization of Pseudomonas cells.In Figure 2, FTIR spectra are shown for samples 1-GA, 1-GA-Ps, 1 and 1-Ps. From Figure 2a, one may notice the occurrence of the characteristic peak of AN $\left(2251 \mathrm{~cm}^{-1}\right)$, not only before, but also after the immobilization of Ps. However, its intensity is lower before immobilization. Since both PAN-co-PMAA and PVA bear hydroxyl groups, numerous bands appear in this respect (a wide band at $3366 \mathrm{~cm}^{-1}$ and two peaks at 3863 and $3745 \mathrm{~cm}^{-1}$ ). Immobilization is confirmed by the appearance of a characteristic peptide band from the bacteria at $1564 \mathrm{~cm}^{-1}$. In the second series of results, FTIR spectra are shown for samples 1 and 1-Ps. From Figure 2b, one may notice in both spectra the occurrence of characteristic peaks from MAA (1715- $\left.1728 \mathrm{~cm}^{-1}\right)$, PVA $\left(3350,3620,3740,3860 \mathrm{~cm}^{-1}\right)$ and AN $\left(2245-2251 \mathrm{~cm}^{-1}\right)$. Similarly, for sample 1-GA, immobilization was confirmed by the same peptide peak $\left(1556 \mathrm{~cm}^{-1}\right)$.

Comparing the results from the two series in Figure 2 (experimental variant 1), it may be concluded that the immobilization of bacteria takes place, regardless of GA activation. Yet, when unmodified beads were used, it may be assumed that a physical adsorption of bacteria took place.

In Figure 3, FTIR spectra are given for samples 2-GA, 2-GA-Ps, 2 and 2-Ps. From Figure 3a, similarly to the previous series of spectra, the peaks characteristic to the raw materials can be observed. In this case also, the immobilization is confirmed by the appearance of the peptide bands $\left(1564 \mathrm{~cm}^{-1}\right)$. 
In the following series, 2 and 2- Ps (Figure $3 \mathrm{~b}$ ), the immobilization of bacteria on hybrid beads took place under a similar manner. Yet, the peak at $3367 \mathrm{~cm}^{-1}$ showed a significantly higher intensity after bacteria immobilization, which is a rather different behavior from the first three series of spectra. A similarity to the previous series refers to the peak at $1556 \mathrm{~cm}^{-1}$ (peptide bond) that appears only after immobilization.


Figure 2. FTIR spectra for samples prepared according to experimental variant 1:

(a)1-GA and 1-GA-Ps; (b) 1 and 1-Ps
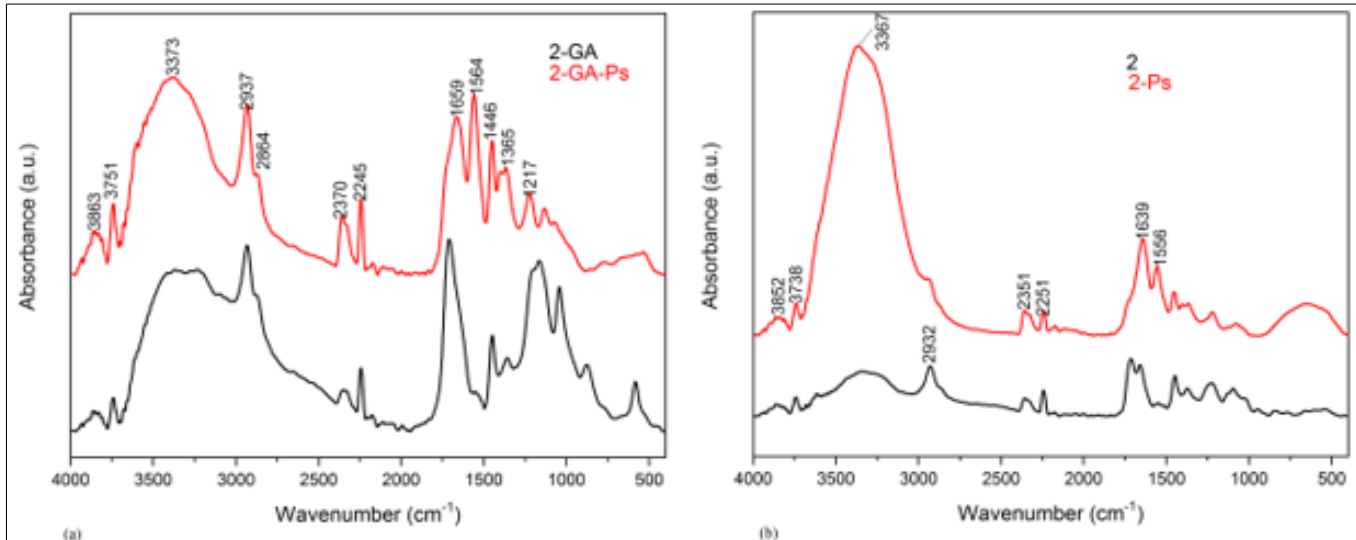

Figure 3. FTIR spectra for samples prepared according to experimental variant 2 :

(a) 2-GA and 2-GA-Ps; (b) 2 and 2-Ps

\subsection{Thermal Gravimetric Analysis (TGA)}

In Figure 4, the TGA curves for samples 1-GA and 2-GA are given before and after contact with Pseudomonas putida (Ps) and Table 6 summarizes the results of thermal analyzes for the samples analyzed in Figure 4. The investigated samples were chemically activated with glutaraldehyde before immobilization.

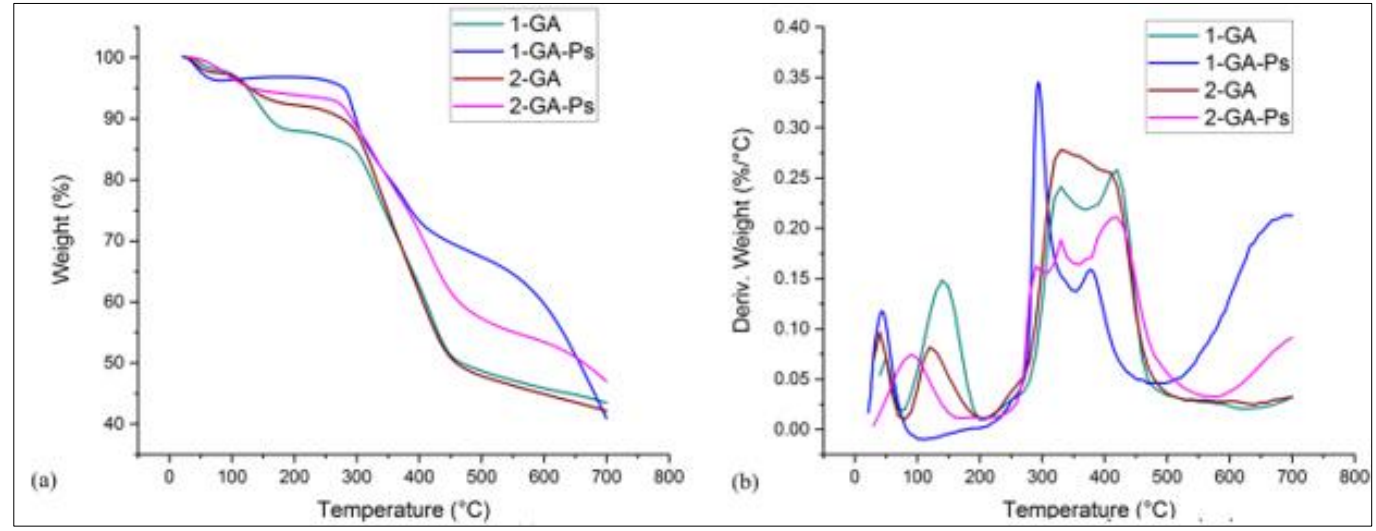

Figure 4. TGA and DTG curves for samples 1-GA and 2-GA, before and after the immobilization of Ps 
Table 6 TGA results for GA activated samples, before and after Ps immobilization

\begin{tabular}{cccccc}
\hline Sample & $\begin{array}{c}\mathbf{T 1}, \\
{ }^{\mathbf{0}} \mathbf{C}\end{array}$ & $\begin{array}{c}\mathbf{T 2}, \\
{ }^{\mathbf{0}} \mathbf{C}\end{array}$ & $\begin{array}{c}\mathbf{T 3}, \\
\mathbf{0}^{\mathbf{C}}\end{array}$ & $\begin{array}{c}\text { T4, } \\
{ }^{\mathbf{0}} \mathbf{C}\end{array}$ & Weight loss, \% \\
\hline 1-GA & 34.0 & 94.4 & 256.7 & 363,2 & 67.86 \\
\hline 1-GA-Ps & 43.8 & 301.8 & 423.2 & & 65.06 \\
\hline 2-GA & 39.9 & 136.8 & 383.0 & 62.43 \\
\hline 2-GA-Ps & 43.5 & 293.6 & 395.3 & 58.11 \\
\hline
\end{tabular}

From Table 6, it can be observed that for both samples 1-GA and 2-GA, the growth of bacteria on the surface of beads unexpectedly leads to an increased stability. Although the weight loss corresponding to 1-GA-Ps is not significantly different from that of 1-GA, for 1-GA-Ps a lower value was recorded. This suggests a better thermal stability for 1-GA-Ps. Moreover, for 1-GA -Ps, thermal degradation occurs only in three stages instead of 4 stages (sample 1-GA) and for 1-GA-Ps, higher temperatures correspond to each degradation stage. For sample 2-GA, the immobilization of Ps was found to yield a higher stability, which is a behavior similar to sample 1-GA.

In Figure 5, the TGA curves for samples 1 and 2 are given before and after Ps immobilization and Table 7 summarizes the results of thermal analyzes for the samples analyzed in Figure 5. Samples were exposed to Ps without being chemically activated with glutardialdehyde.
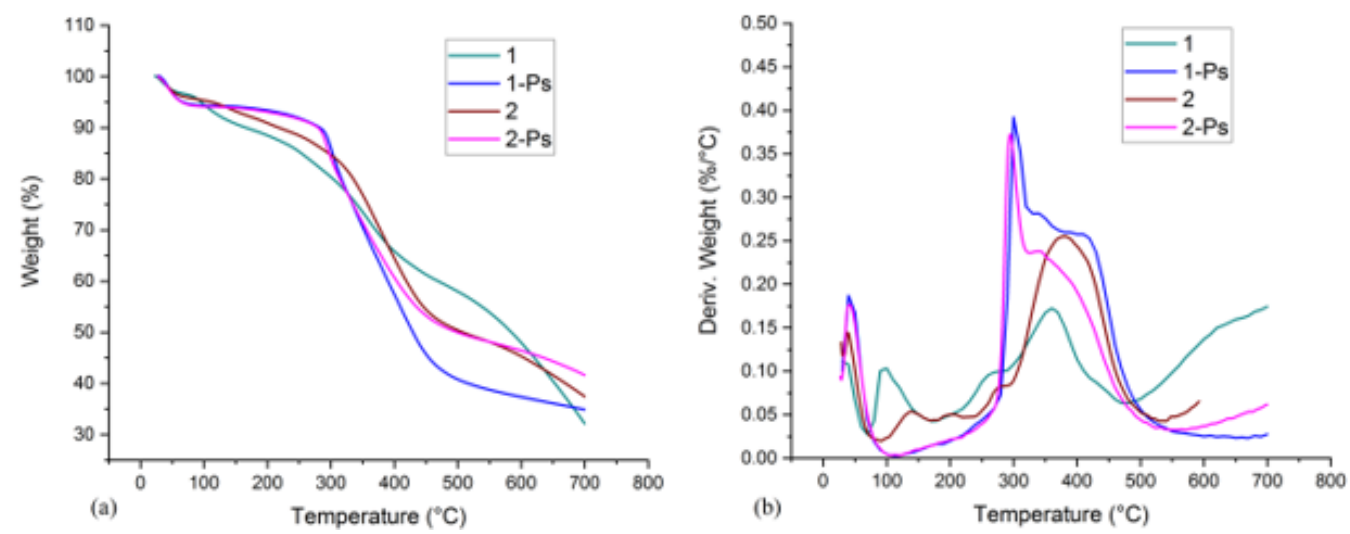

Figure 5. TGA and DTG curves for samples 1 and 2, before and after the immobilization of Ps

Table 7. TGA results for unmodified samples, before and after Ps immobilization

\begin{tabular}{cccccc}
\hline Sample & $\mathbf{T 1}$ & $\mathbf{T 2 ,}$ & $\mathbf{T 3 ,}$ & $\mathbf{T 4 ,}$ & Weight loss, \% \\
& ${ }^{\mathbf{0}}$ & ${ }^{\mathbf{0}} \mathbf{C}$ & $\mathbf{0} \mathbf{C}$ & ${ }^{\mathbf{C}}$ & \\
\hline 1 & 47.8 & 141,9 & 324,1 & 423,4 & 56.58 \\
\hline $1-\mathrm{Ps}$ & 44.0 & 293,54 & 380,9 & & 58.82 \\
\hline 2 & 41.6 & 119,0 & 320,5 & 418,3 & 57.88 \\
\hline $2-\mathrm{Ps}$ & 89.8 & 285,6 & 327,8 & 424,4 & 52.93 \\
\hline
\end{tabular}

Different from samples 1-GA and 2-GA, for sample 1, immobilization of Ps results in a lower thermal stability. Although the increase of the weight loss value was only by $2.2 \%$ ( $58.8 \mathrm{vs} 56.6 \%$ ), an increase trend occurred after immobilization, showing that immobilization leads to a reduction in thermal stability. Moreover, the final degradation stage takes place at a lower temperature $\left(380.9\right.$ vs $\left.423.4{ }^{0} \mathrm{C}\right)$ for 2-Ps. In the case of sample 2, similar to samples 1-GA and 2-GA, exposure to bacteria leads to enhanced thermal stability. Although both 2 and 2-Ps degrade in 4 steps, the temperature corresponding to each step is higher for the 2-GA-Ps sample. The weight loss is also lower for 2-Ps sample (52.93 vs. $57.88 \%)$. 


\subsection{Scanning Electron Microscopy (SEM) and ability of Pseudomonas putida to withstand beads}

In the first experiment, the beads (1-GA) were incubated with Ps in a Heidolph Unimax 1010 orbital shaker incubator for $24 \mathrm{~h}$ at room temperature. The dynamics of cells number may be summarized as follows: $\mathrm{N}_{\text {initial }}=2.83 \times 10^{10} \mathrm{CFU} / \mathrm{ml} ; \mathrm{N}_{\text {end }}=1.22 \times 10^{10} \mathrm{CFU} / \mathrm{mL}$.

Colony-Forming Unit (CFU) is a unit used to estimate the number of viable bacteria cells in a sample. This decrease in the number of CFU may be attributed to activity loss after immobilization, which is normal, as a part of the active sites of Ps are consumed during immobilization. To prove the viability of Pseudomonas cells, the beads exposed to bacteria were placed on a minimal culture medium in Petri plates. From Figure 6, it may be observed that bacterial cells were viable and a good growth was observed even in contact with beads. The results of cells measurement and growth on 1-GA-Ps were supported by SEM investigations (Figure 7). From Figure 7, it may be observed that Ps proliferation takes place on the surface of 1-GA, which is in a good agreement with cells count measurement.

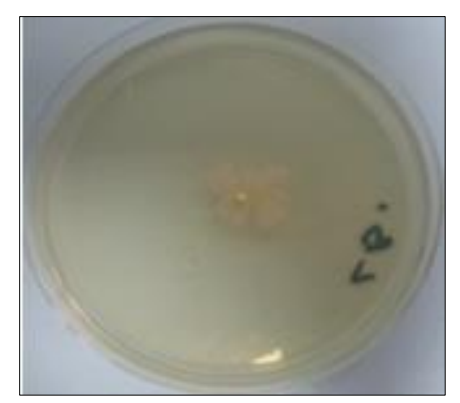

Figure 6. 1-GA-Ps on minimal solid medium in Petri plate

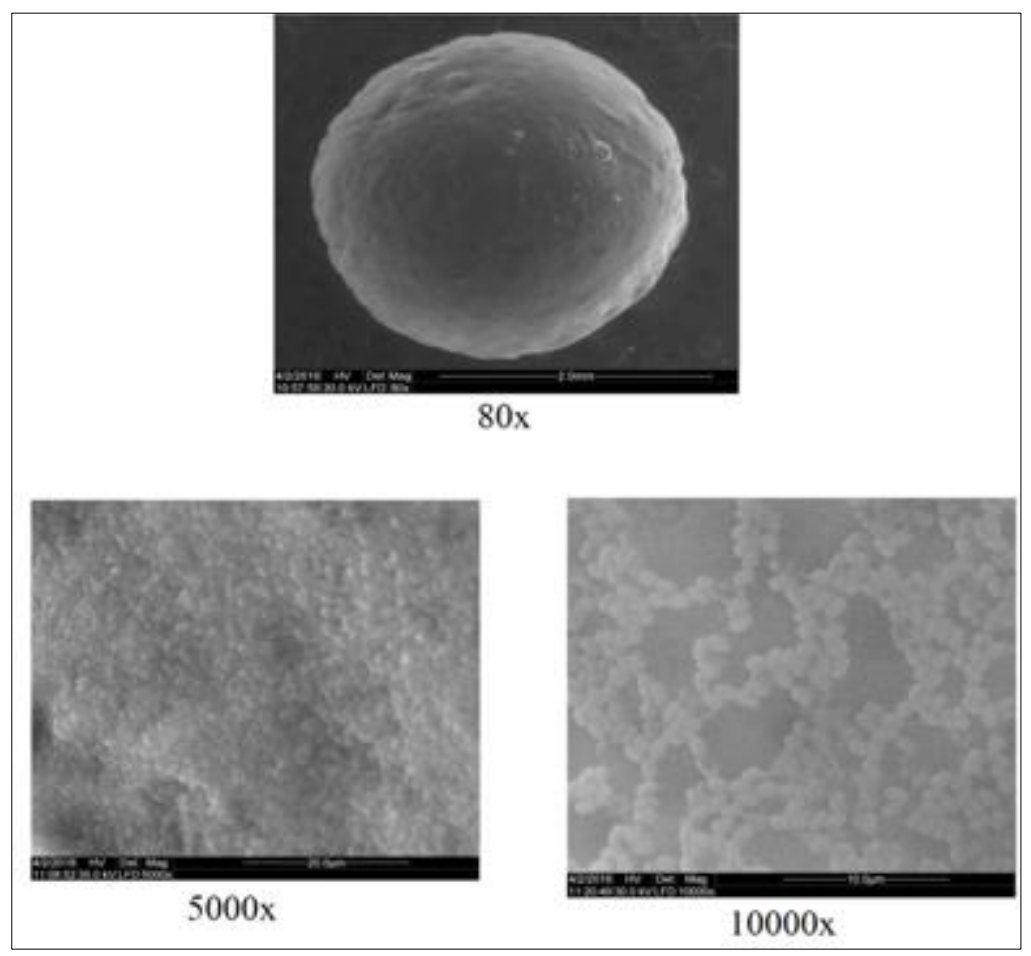

Figure 7. SEM images of sample1-GA-Ps. After incubation, the bead was thoroughly washed with sterile water and deposited on minimal solid medium on Petri plate (white arrow - bacterial cells growing on bead surface)

In the second experiment (Figure 8), the incubation period was extended to $48 \mathrm{~h}$. In this study, the dynamics of cells number followed the same rule, decreasing from $\mathrm{N}_{\text {initial }}=1.92 \times 10^{10} \mathrm{CFU} / \mathrm{mL}$ to $\mathrm{N}_{\text {end }}$ $=1.26 \times 10^{8} \mathrm{CFU} / \mathrm{mL}$. This decrease confirms once again that immobilization occurred, as a part of the 
active sites are consumed. In this case also, results were corroborated with SEM images. The aspect of samples depends on the magnification. Hence, the most obvious evidence of Ps growth was observed at 1000x and 4000x. The simple washing procedure with sterile water yielded significant changes in the beads surface that may be attributed to removal of physically immobilized (non-covalently immobilized) Ps.

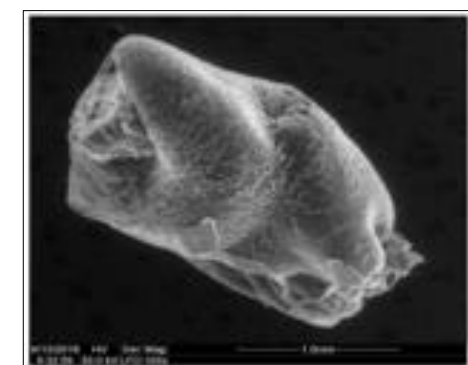

$100 \mathrm{x}$

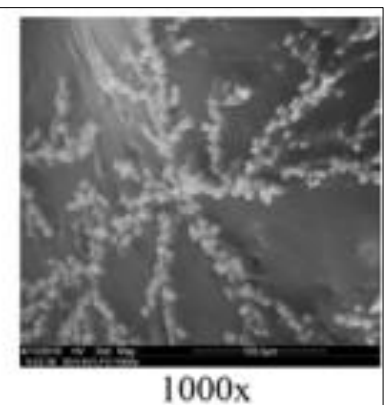

$1000 x$

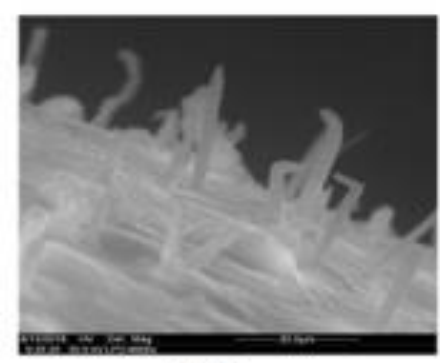

$4000 x$

Micrographs of beads after being exposed to Ps, before washing

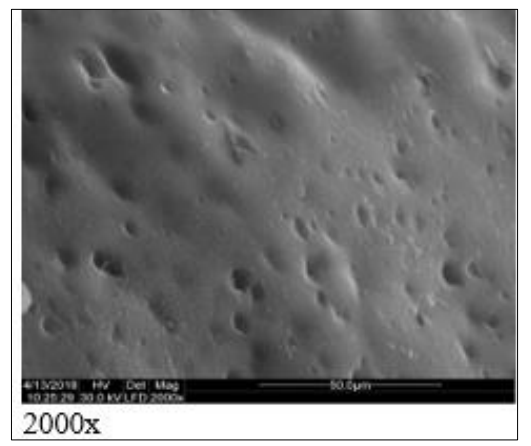

Micrographs of beads after being exposed

to Ps and after washing with sterile water

Figure 8. SEM images for sample 1-GA-Ps, after 48h of contact

\subsubsection{Biodegradation of Acid Blue 93}

To investigate the biodegradation of the dye, UV spectra were recorded. Therefore, samples 1-GAPs and 2-GA-Ps were contacted with a dye solution (1\% in water) and UV spectra were recorded after different contact times $(24,72$ and $144 \mathrm{~h}$, respectively). For a thorough, investigation, the UV-Vis spectrum of the pure dye (not exposed to bacteria was recorded). This reference is denoted with $0 \mathrm{~h}$. In Figure 9, the corresponding spectra are shown. 


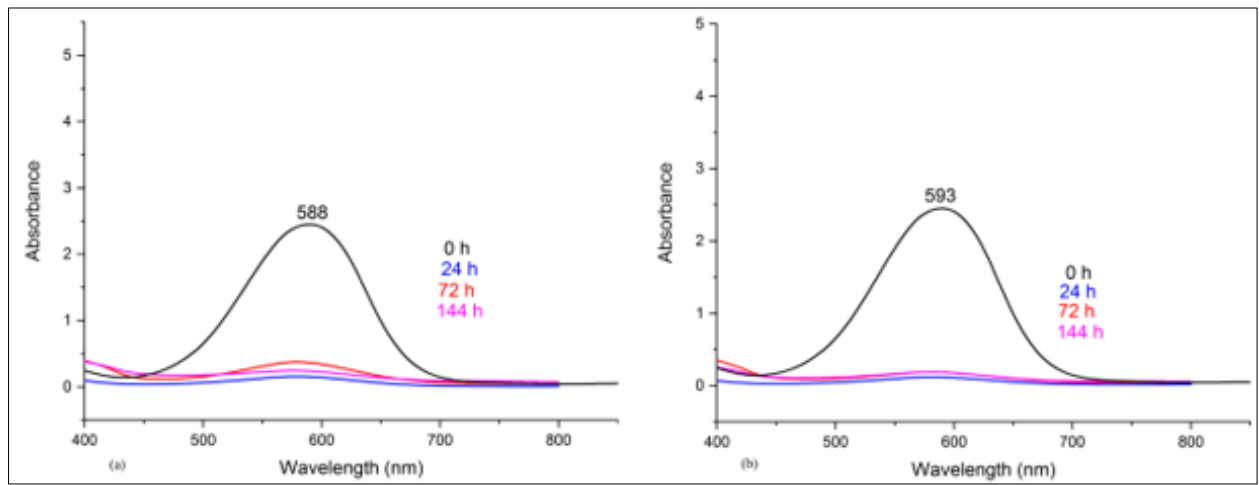

Figure 9. UV-Vis spectra for samples 1-GA-Ps (a) and 2-GA-Ps (b), respectively, at different contact times $(24 \mathrm{~h}, 72 \mathrm{~h}, 144 \mathrm{~h})$ contact with Acid Blue

The dye displays a characteristic peak at $590 \mathrm{~nm}$. This result is in a good agreement with literature information on Acid Blue 93 [24]. In all spectra, the intensity of the peak registered at 590nm significantly decreased as compared to the reference $(0 \mathrm{~h})$. This may be regarded as a result to dye adsorption on the surface of the beads. Therefore, in the first $24 \mathrm{~h}$ the dye is adsorbed almost completely and further extension of the contact time to $72 \mathrm{~h}$ or $144 \mathrm{~h}$ no longer leads to dye degradation, but more to a desorption. Interestingly is the fact that both experimental variants ( 1 and 2$)$ lead to similar results on dye adsorption.

\section{Conclusions}

The immobilization of Pseudomonas putida cells on the magnetic hybrid beads was successfully performed, regardless of the considered experimental variant, i.e. GA- activated beads and unmodified beads. However, for the unmodified beads, the immobilization of bacteria was only physical and the bacteria layer was easily washed with water. The indisputable proof that the immobilization took place was given by the important changes in the chemical composition (FTIR, the appearance of the peak characteristic of the peptide bonds), in the thermal behavior (for samples activated with GA the immobilization improves the thermal stability) and in the morphology of beads surface after immobilization. The influence of raw materials addition order to prepare the composites was better emphasized by TGA results than by FTIR analysis. It seemed that series 2 of beads was more homogenous. Pseudomonas putida was able to grow even after being immobilized on beads, as shown by SEM images and CFU values. The GA- activated beads with immobilized Ps were successfully used for the biodegradation of Acid Blue 93 dye. Only slight differences were recorded by UV-Vis between the two experimental variants of beads in the biodegradation study.

Acknowledgements: The authors would like to thank the EU, JPI Oceans and the Romanian National Authority for Scientific Research and Innovation UEFISCDI for funding, in the frame of the collaborative international consortium (BIOSHELL, contract no. 157/2020) financed under the ERANET Cofund Bluebio 2019 Call, to project PFE 31/2018 of ICECHIM and to the PN 19.23.02.01 core project of ICECHIM.

\section{References}

1.GEVRENOVA, R., Determination of natural colorants in plant extracts by high-performance liquid chromatography, J. Serb. Chem Soc.75, 2010, p. 903

2.SIMS, J. L., SIMS, R. C., GINN, J. S. Bioengineering for Water Clean: State-of-the-Art Assessment, Utah State University, Logan, November 1992 
3.MOAWAD, H., DARWESH, O. M., ABD EL- RAHIM, W. M., BARAKAT, SEDIK, O. S., M. Z. Microbial biodegradation of Reactive Blue (RB) textile azo dye in sequential anoxic/aerobic bioreactor, International Journal of Advanced Research,1, 2013, p. 272.

4.BAYOUMI, M. N., AL- WASIFY, R. S., HAMED, S. R. Bioremediation of textile wastewater dyes using local bacteria isolates, Int. J. Curr. Microbiol. App. Sci. 3, 2014, p. 962

5HE, S., ZHONG, L., DUAN, J., FENG, Y., YANG, B., YANG, L., Bioremediation of wastewater by iron oxide-biochar nanocomposites loaded with photosynthetic bacteria, Front. Microbiol. 8, 2017, p. 823, doi: 10.3389/fmicb.2017.00823

6.DINU, M. V., LAZAR, M. M., DRAGAN, E. S., Dual ionic cross-linked alginate/ clinoptilolite composite microbeads with improved stability and enhanced sorption properties for methylene blue, React. Funct. Polym, 116, 2017, p. 31

7.HEMA, N., SURESHA, S., Bioremediation of textile dye effluent by shewanella Putrefaciens, Int J. Pharm. Biol. Sci.4, 2014, p. 109

8.RANI, B., KUMAR, V., SINGH, J., BISHT, S., TEOTIA, P., SHARMA, S., KELA, R., Bioremediation of dyes by fungi isolated from contaminated dye effluent sites for bio-usability, Braz. J. Microbiol 45, 2014, p. 1055

9.OGUGBUE, C. J., SAWIDIS, T., Bioremediation and detoxification of synthetic wastewater containing triarylmethane dyes by Aeromonas hydrophila isolated from industrial effluent, SAGEHindawi Access to Research, Biotechnol. Res. Int. Volume 2011, Article ID 967925, 11 pages, doi: $10.4061 / 2011 / 967925$

10.DARWESH, O. M., MOAWAD, H., ABD EL- RAHIM, W. M., Application of nanostructured microbial enzyme for bioremediation of industrial wastewater, Int. J. Water Res. Arid Environ.4, 2015, p. 37

11.M. GRAY, The activity of immobilized anaerobic bacteria in the treatment of industrial wastewater, lucrare de licenta, Shanghai Jiao Tong University, 2008

12.SHAH, M. P., PATEL, K. A., NAIR, S. S., DARJI, A. M., Microbial degradation of Textile Dye (Remazol Black B) by Bacillus spp. ETL-2012, J. Bioremed. Biodeg. 4, 2013, doi: 10.4172/21556199.100180

13.LAWRENCE, S., KANNAN, R., Textile dye removal from wastewater effluents by using potential microbes, Int. J. Sci. Res.4, 2015, p. 1147

14.SAROJ, S., KUMAR, K., PAREEK, N., PRASAD, R., SINGH, R. P., Biodegradation of azo dyes Acid Red 183, Direct Blue 15 and Direct Red 75 by the isolate Penicilliumoxalicum SAR-3, Chemosphere 2014, 107, 240- 248

15.OMAROVA, E. O., LOBAKOVA, E. S., DOLNIKOVA, G. A., NEKRASOVA, V. V., IDIATULOV, R. K., KASHCHEEVA, P. B., PEREVERTAILO, N. G., DEDOV, A. G., Immobilization of bacteria on polymer matrices for degradation of crude oil and oil products, Moscow University Biological Sciences Bulletin 67, 2012, p. 24

16.PANDEY, J., CHAUHAN, A., JAIN, R. K. Integrative approaches for assessing the ecological sustainability of in situ bioremediation, FEMS Microbiol. Rev. 33,2009, p. 324

17.SANDU, T, SARBU, A., DAMIAN, C.M., MARIN, A., VULPE, S., BUDINOVA, T., YARDIM, M.F., SIRKECIOGLU, A., Preparation and Characterization of Membranes Obtained from Blends of Acrylonitrile copolymers with Poly(vinyl alcohol), J. Appl. Polym. Sci., 2014,

DOI: 10.1002/APP.41013

18.GARILĂ (FLOREA), A.M, IORDACHE, TV, SANDU, T., ZAHARIA, A, RADU, AL, BRANGER, C, BRISSET, H, STOICA, EB, APOSTOl, S, SÂRBU, A, Molecularly Imprinted Polymer Pearls Obtained by Phase Inversion for the Selective Recognition of Hypericin, Mater. Plast., 56(2), 2019, 315 19.FLOREA, AM, IORDACHE, TV, ZAHARIA, A, GEORGESCU, B, VOICU, AE, TSYNTSARSKI, B, HUBCA, SARBU, A, Evaluation of Molecularly Imprinted Polymer Pearls for Selective Isolation of Hypericins, Mater. Plast., 54(3), 2017, 495 
20.GARILĂ (FLOREA), AM, IORDACHE, TV, BRANGER, C, BRISSET, H, LAATIKAINEN, K, CIURLICA, AL, ZAHARIA, A, RADU, Al, COMAN, AE, FLOR, S, SÂRBU, A, The Effect of Monomers on the Recognition Properties of Molecularly Imprinted Beads for Proto-hypericin and Protopseudohypericin, Mater. Plast., 57(1), 2020, 100

21.YADAV, R. S., HAVLICA, J., MASILKO, J., KALINA, L., WASSERBAUER, J., HAJDUKOVA, M., ENEV, V., KURITKA, I., KOZAKOVA, Z., Effects of annealing temperature variation on the evolution of structural and magnetic properties of $\mathrm{NiFe}_{2} \mathrm{O}_{4}$ nanoparticles synthesized by starch- assisted sol-gel auto- combustion method, J. Magn. Magn. Mater.394, 2015, p. 439

22.IVANOV, T., IVANOVA, M., KAMBUROV, M., Magnetic poly(acrylonitrile-co-acrylamide) microparticles for immobilization of trypsin, International Review of Chemical Engineering (I. RE. CH. E), 2009, 1, 4, p. 308.

23.SAFARIK, I., SAFARIKOVA, M., Magnetic techniques for the isolation and purification of proteins and peptides, Bio Magnetic Research and Technology, 2004, 2, p.7.

24.SAFARIK I., POSPISKOVA K., A simple extraction of blue fountain ink dye (Acid blue 93) from water solutions using Magnetic Textile Solid-Phase Extraction, Separation Science Plus, 2018, 1, p. 48.

$\overline{\text { Manuscript received: } 17.08 .2020}$ 